\title{
Surface roughness evaluation after machining wear resistant hard coats
}

\author{
Katarina Monkova ${ }^{1, *}$, Peter Monka ${ }^{1,2}$, Jiri Cesanek ${ }^{2}$, Jan Matejka ${ }^{2}$ and Vladimir Duchek ${ }^{2}$ \\ ${ }^{1}$ Technical University of Kosice, Faculty of Manufacturing Technologies with the seat in Presov, \\ Sturova 31, 08001 Presov, Slovakia \\ ${ }^{2}$ Faculty of Mechanical Engineering, University of West Bohemia, Univerzitni 8, 30614 Pilsen, \\ Czech Republic
}

\begin{abstract}
The technology HVOF - High Velocity Oxygen Fuel was used to spray the alloy Stellite 6 for the purpose of this research. This method is based on using high velocity spraying flame. The article deals with the evaluation of surface quality after machining of wear resistant hard coats. The goal of the authors was to understand the main factors that influence final surface quality at machining of the coatings from Stellite 6 . The findings of experiment have confirmed that there have been obtained very important information about machining of this alloy at the specific type of workpiece. Authors have evaluated the quality of the surface not only by means of Abbott curve, but they have also observed the dependency of arithmetical mean roughness value on both cutting edge radius and feed. The analyses of cutting tips wear at changeable inserts of tools have shown that the typical wear appears in the form of a notch.
\end{abstract}

\section{Introduction}

The machinability of a material is generally defined by the surface roughness quality and the surface integrity obtained, the tool life, heat generation in the cutting zone, chip formation difficulties, material removal rate and power consumption, machine tool dynamics, and other parameters involved in metal machining. Since the machinability of a material largely depends on its physical, chemical and metallurgical characteristics, the selection of cutting regimes, the right cutting tools and adequate machine tools is the appropriate solution to the most economically effective and sustainable manufacturing. [1]

The major quality assurance of machined parts checks geometric accuracy, surface roughness and residual stress levels of the machined parts. All these parameters and the factors related to surface integrity are largely dependent on the selected cutting regimes for machining a given material using a given cutting tool on a certain machine tool. Therefore, researching for optimal cutting regimes/parameters for machining a certain material using specific cutting inserts is the topmost priority in machining research. All other research

\footnotetext{
*Corresponding author: katarina.monkova@tuke.sk
} 
relevant to machining would be accurate and effective if the optimal cutting regimes have been used for machining the samples under investigation. [2,3]

Special category of the machined components creates the parts, surfaces of which are deposited. Deposits can be made by various technologies. They are organized in Fig. 1 according to the dependence of jet temperature on the particle impact velocity. [4]

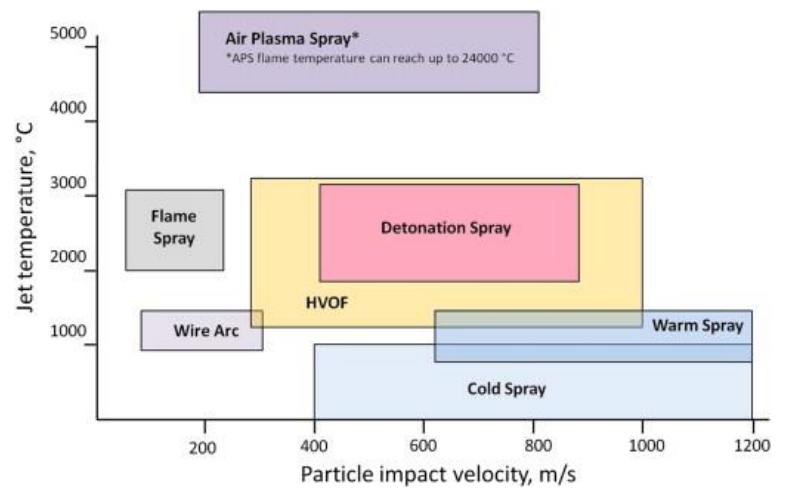

Fig. 1. The technologies used for hard coatings deposition [4].

One of the technologies for deposition and for surface quality improvement is High Velocity Oxygen Fuel (HVOF) that was used for the purpose of this research. HVOF coating is a thermal spray process used also to improve or restore wear resistance and corrosion protection. Molten or semi-molten materials are sprayed onto the surface by means of the high temperature, high velocity gas stream, producing a dense spray coating which can be ground to a very high surface finish. [5]

The principle of HVOF spraying technology is shown in Figure 2 [4].

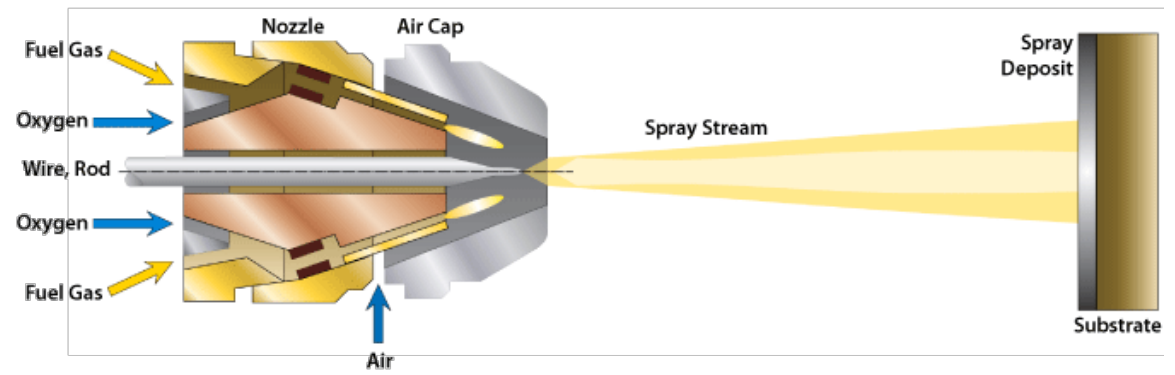

Fig. 2. The principle of HVOF technology [6].

One of the key benefits of this system's high velocity is the extremely high coating density and low oxide content. The low oxides are due partly to the speed of the particles spending less time within the heat source and partly due to the lower flame temperature (around $3,000{ }^{\circ} \mathrm{C}$ ) of the heat source compared with alternative processes. Generally, the parts deposited by coats are often characterized as difficult-to-machine. They are materials which produce excessive tool wear, excessive cutting forces causing high heat generation, difficulties in chip formation resulting in poor surface finish during machining operations. As well as producing excellent bond strength, some HVOF coatings can be sprayed very thick due to the exceptionally high velocities producing coatings in compression instead of tension. This enables materials such as carbide to be applied very quickly in excess of $6 \mathrm{~mm} .[6,7]$ 
Coatings produced using HVOF have outstanding characteristics, even above other thermal spray processes, that include: high density, optimum hardness, higher coating thickness (coatings exhibit greater coating thickness limits than plasma, combustion or wire coatings of the same coating material, beneficial residual stress, excellent wear resistance, superb corrosion resistance and exceptional metallurgical properties, fine surface finishes (coatings can be machined, ground, lapped, honed or super finished to produce very high surface finishes to precise tolerances) [8].

\section{Deposited material - Stellite 6}

Nowadays, many Stellite alloys are produced with combinations of various amounts/proportions of cobalt, chromium, molybdenum, tungsten, titanium, nickel, iron, aluminium, carbon, boron, manganese, phosphorus, silicon and sulphur. By virtue of their low magnetic permeability and excellent anticorrosive properties some of the stellites are extremely suitable for medical surgery, dental implants, bone replacement, artificial heart valves, and heart pacemakers [9].

The distribution of chemical composition with spectral analysis of deposited material Stellite on the selected area of sample is presented in Fig. 3 [10].

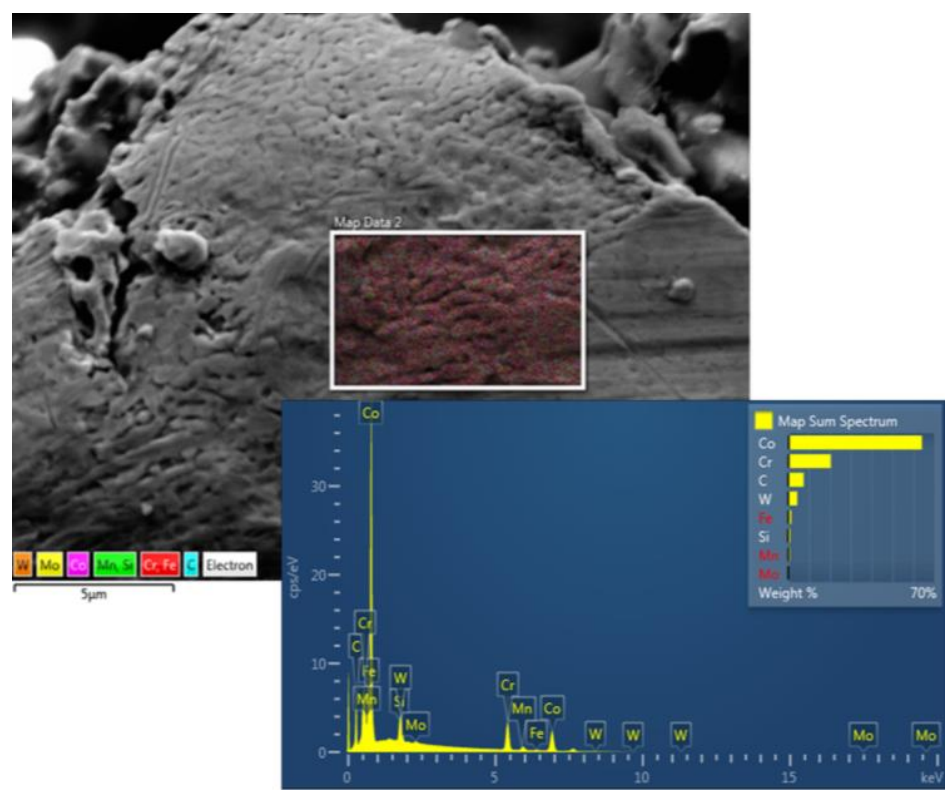

Fig. 3. Chemical composition and spectral analysis of deposited material Stellite [10].

Due to their high hardness and good ductility, highly dense molecular structure, harder and more regularly organised carbides, lower thermal conductivity, tendency to resist plastic deformation having lower Young's modulus, stellites are categorized as difficult-tomachine materials due to their poor machinability. [11,12]

There is a good prospect to improve the machining technique and the technology of stellites to overcome the machining difficulties. As parts made of stellites are widely used in various industries and very popular in specific applications, it is a big drawback that adequate machining processes for stellites have not yet been developed other than the costly and time-consuming technique of grinding. However, an attempt has been made to reveal the optimal machining parameters (cutting speed, feed rate and depth of cut) for a lower 
value of surface roughness for the purpose of successful machining of Stellite 6 using new grades of coated and uncoated carbide inserts with various nose radii [13-15].

\section{Experiments}

\subsection{Conditions of coating process}

As it was mentioned above, powdered Stellite 6 was used as the coating material. As an energy carrier was selected Nitrogen with flow rate $6.5 \mathrm{l} / \mathrm{h}$. The spraying distance was $360 \mathrm{~mm}$ and the layer of deposited coating was $0.4 \mathrm{~mm}$.

The porosity of deposited coating was measured at randomly selected three different locations and the average was used for further analysis. The results revealed that the majority of pores present in the HVOF coatings were type A pores $(0-10 \mu \mathrm{m}$ in size). These pores were formed because of interactive effects of particles and the gaseous medium. The porosity was evaluated lower than $1 \%$ of a volume.

In the next step, mechanical properties and micro-hardness of deposited coating were measured. HR $15 \mathrm{~N}$ hardness was measured on the top surface of the coating, while average of 8 measurements were done. The measured value of $82.8 \pm 3.1$ corresponds to approximately $45 \mathrm{HRC}$. Micro-hardness HV0,3 was measured in the cross section, at half the thickness of the coating. Average of 15 measurements were performed with result value of $650 \pm 75$.

\subsection{Conditions of experiments at the machining}

Based on the research of available literature and based on previous experience of experts at Regional Laboratory Institute of Technology, the following processing factors were selected: $[10,16]$

1) Tools

a) Inserts (changeable) - with circle shapes made from cutting material CERMET with geometry as it is shown in Fig. 4. Next parameters of inserts - diameter of $\varnothing 12 \mathrm{~mm}$, radius of the cutting edge with values of 10/14/18 microns.

b) Tool holder - Capto modular system with HSK cone.
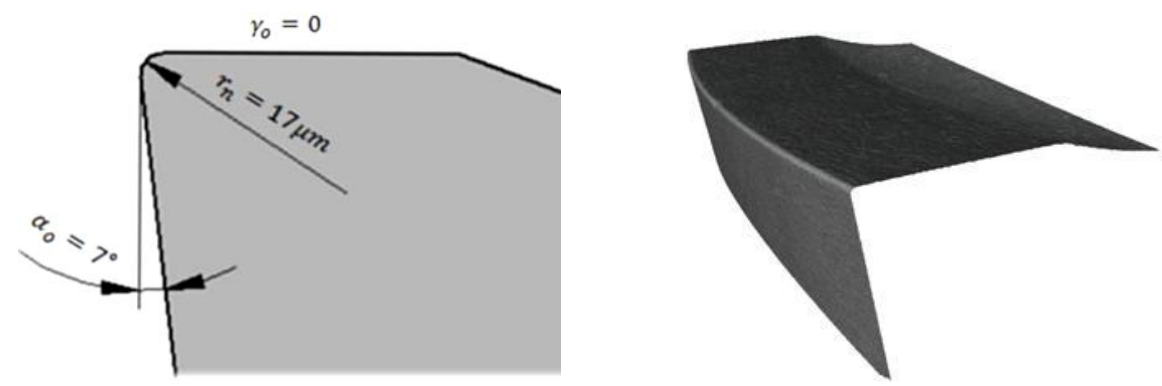

Fig. 4. Macro-geometry of insert in orthogonal plane and 3D scan of real insert.

2) Workpiece - steel cylinder from material 12050.1 with diameter $60 \mathrm{~mm}$ deposited with Stellite 6by means of HVOF spraying technology (sprayed in the average thickness of $0.45 \mathrm{~mm})$.

3) The machine - DMG MORI CTX beta 1250.

4) Technological factors of experiments

a) cutting speed of 25 meters per minute 
b) Depth of cut $0.2 \mathrm{~mm}$

c) Feeds: $0.15 / 0.30 / 0.45 \mathrm{~mm}$

d) Cooling - two variants: with cooling pressure of 100 bars / without cooling

Observed parameters were arithmetical average deviation from a mean line $R a$ and tenpoint height of irregularities $R z$.

Process of machining was realized at following cutting conditions: cutting speed $v_{c}=25 \mathrm{mmin}^{-1}$, feed per revolution $f=0.15 \mathrm{~mm}$, cutting depth $a_{p}=0.2 \mathrm{~mm}$ and cooling at the pressure 100 bars.

\subsection{Results of experiments}

Experiments were carried out in a combination of factors described above. The selected type of workpiece (represented by a combination of structural steel and thermal spray of alloy Stellite 6 by technology HVOF) has been characterized by markedly different behaviour in comparison with the machining of this type of material in casted or moulded state. At many samples, it has occurred to the separating of material at borders of joined structural units of the coating layer and not at the path that was specified by kinematic join between the tool tip and rotating workpiece. Characteristic surface after machining of coated samples no. 13 is shown in Figure 5.

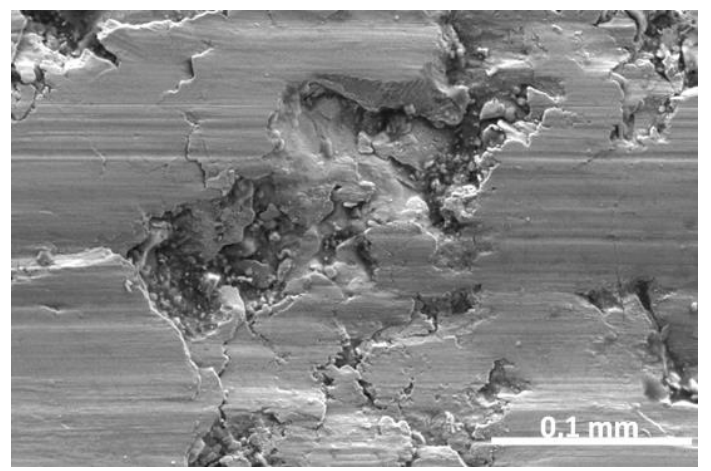

Fig. 5. Machined surface of coated sample.

At the machining with unsuitable conditions, it occurs to the oscillation of machining set, what influence stability of the machining process and surface roughness, of course. The traces of cutting tool on top surface of the workpiece are visible in Fig. 6.

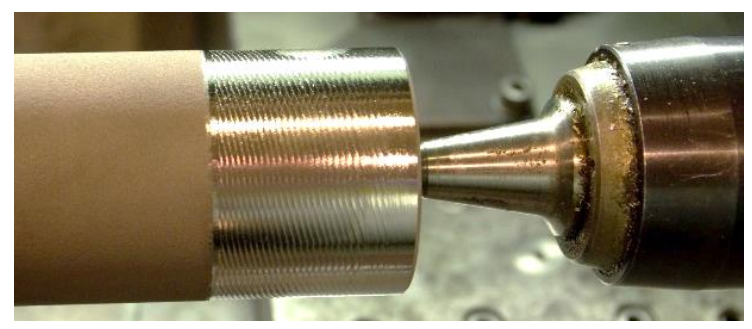

Fig. 6. Traces on the top surface of the workpiece.

Achieved results were statistically processed, while remote values have been excluded and they are represented by dependencies of surface roughness on cutting tip radius and on the feed. The obtained graphs are shown in Figures 7 and 8.

The plots point to the following statements: 
- Supposed significant influence of observed characteristics of surface roughness on increasing of feed per revolution.

- The surface roughness is slightly increasing with the increasing radius of cutting edge.

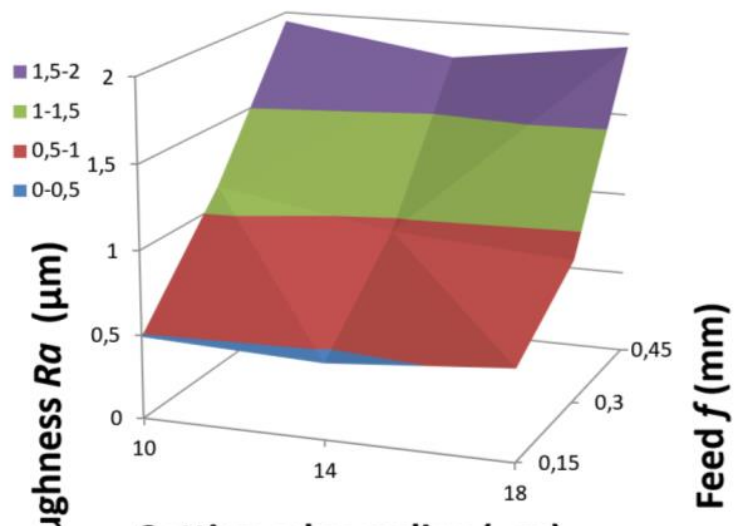

Cutting edge radius $(\mu \mathrm{m})$

Fig. 7. Dependence of arithmetical average deviation from a mean line $R a$ on cutting edge radius and feed.

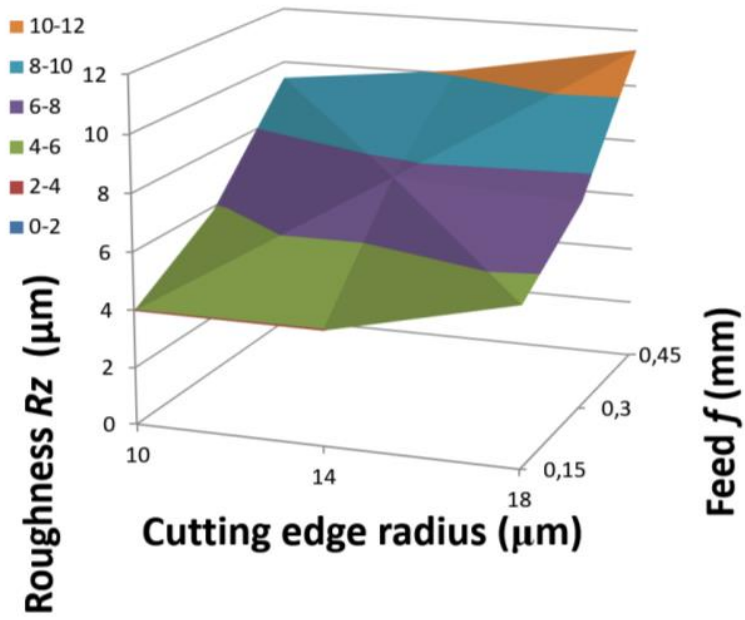

Fig. 8. The dependence of ten-point height of irregularities $R z$ on cutting edge radius and feed.

The Abbott curve was also used for evaluation of observed surface. It simulates the effects of wear or running-in, giving information on the material and void volumes of the surface topography, on damaging rate of the superficial layer, on bearing capacity and fluid retention capacity of the studied materials. Utility of Abbott curve in tribological evaluation of a surface becomes evident when studying surfaces of same material but obtained with different technologies: these surfaces may have the same $R a$ but different Abbott curves. The reasons of these differences may be: different shapes of the asperities, their distribution on height but also their spacing ranges. Studying the Abbott curves after functioning on laboratory models reveals some specific tendencies that may be correlated with other tribological parameters as wear and friction 
coefficient, and they may recommend range of load, speed or combination of them for actual application $[16,17]$.

The obtained Abbott curve together with the detail of coated surface after machining sample n. 13 is shown in Fig. 9.

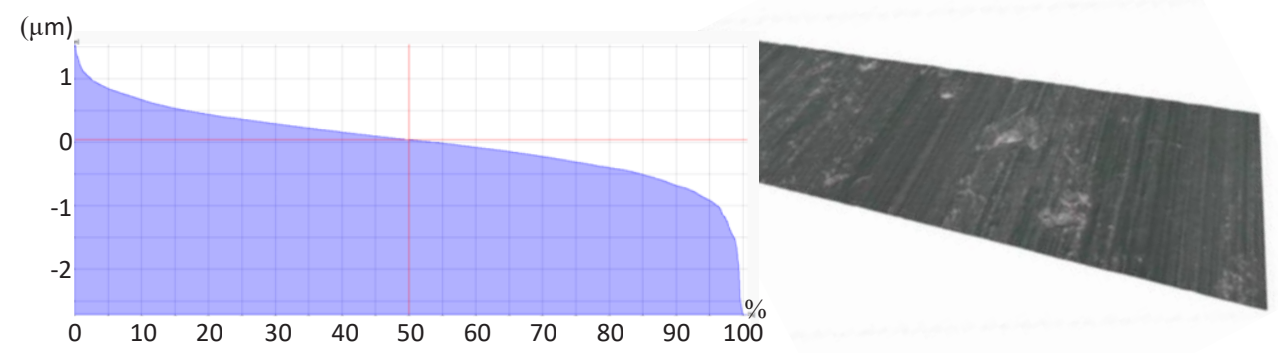

Fig. 9. Abbott curve together with the detail of coated surface after machining sample num. 13.

\section{Conclusions}

Thermal spray coating is an attractive technique as it offers a wide choice of materials and processes that have a reduced impact on the environment when compared to conventional plating processes. When thermally-sprayed coatings are porous, especially with connected porosities, they are not very suitable for corrosion protection. This situation can be drastically improved by curing their inter-connected porosities through sealing or by posttreatments that are generally thermal. The sealing or post-treatment process depends on the coating material and its service conditions and, also, on the cost that the customer can accept $[18,19]$.

During experiments, it has not been proved the fact that in the case of intensive cooling (with pressure 100 bars) would be achieved markedly better quality of surfaces than in the case of dry machining.

Based on the experiment results it can be stated that in some cases very different values of surface roughness have achieved, which may also be caused by different structure of thermal spray, e.g. due to a various number of pores or due to the smaller size of cohesive forces, leading to an easier extraction of particles in the course of machining.

The analyses of cutting tips wear at changeable inserts of tools have shown that the typical wear was $\mathrm{VB}_{\mathrm{B}}$ type in combination with $\mathrm{VB}_{\mathrm{N}}$ wear in the form of a notch (according to the standard ISO 3685) and there also occurred slight imprint of the face near to the cutting edge. The findings of experiment have confirmed that there have been obtained very important information about machining of alloy Stellite 6 at this specific type of workpiece, where following characteristics were required: very low values of the surface roughness, the mean depth of cut $0.2 \mathrm{~mm}$, macrostructure of joined clusters with variable consistency on the border.

The effort of authors' future research will be focused on the quality of machining surface improvement. Another type of cutting material and different geometry of cutting tips will be tested along with specification of the most suitable parameters, at which the best surface quality will be achieved.

The paper originates with the direct support of Ministry of Education of Slovak republic by grants VEGA 1/0614/15, KEGA 087TUKE-4/2015, KEGA 007TUKE-4/2018 and thanks to project ED2.1.00/03.0093 - Regional Technological Institute covered by the European Regional Development Fund and the state budget of the Czech Republic. 


\section{References}

1. B. Matesa, D. Kozak, A. Stoić, I. Samardžić, Metalurgija 50 (4), 227 (2011)

2. G. Krolczyk et al., Metalurgija 54 (1), 91 (2015)

3. P. Twardowski et al., Advances in Mechanical Engineering 7 (6), 1 (2015)

4. Grigoriev, S. et al., Surface and Coatings Technology 268, 77 (2015)

5. A. Panda et al., Applied Mechanics and Materials 616, 183 (2014)

6. E. Gawronska, N. Sczygiol, Transactions on Engineering Technologies 17 (2015)

7. T. Temucin et al., Technical Gazette 20 (5), 787 (2013)

8. J. Petru et al., Tehnicki Vjesnik 20 (2), 225 (2013)

9. J. Jurko, Adv. Comp. Sci. Edu. Appl. 202 (2), 338 (2011)

10. P. Monka, et al., Proceedings of Manufacturing Technology conference, Pilsen, 1 (2017)

11. H. Shahanur et al., Int. J. of Engineering Materials and Manufacture 1 (2), 35 (2016)

12. S. M. Stojadinovic, V. D. Majstorovic, FME Transactions 42 (3), 249 (2014)

13. P. Fauchais, A. Vardelle, Advanced Plasma Spray Applications, InTech, 250 (2012)

14. R. Cep et al., Key Engineering Materials 581, 341 (2014)

15. P. Monka, P., Int J Adv Manuf Technology 85, 2325 (2016)

16. M. Moravek, Influence of input characteristics micro and macro structure of coat with selected type on its machinability by the tool with defined tip geometry, Diploma Thesis, Department of Machining Technology, University of West Bohemia in Pilsen (2016)

17. M. Ungureanu et al., Proceedings of the $5^{\text {th }}$ Central European Conference in Regional Science (CERS), 1112 (2015)

18. D. Kinik et al., Tehnicki Vjesnik 22 (2), 351 (2015)

19. S. Malotova, Manufacturing Technology 16 (1), 168 (2016) 